\title{
Misconceptions about sexual intercourse during pregnancy: cognitive-behavioral counseling in prenatal care
}

\author{
MARYAM KHEIRI ${ }^{1, A-G}$, KATAYON VAKILIAN ${ }^{2, A, D, E}$ \\ ORCID ID: 0000-0002-6035-0796
}

${ }^{1}$ Nursing and Midwifery School, Arak University of Medical Sciences, Arak, Iran

${ }^{2}$ Medical School, Arak University of Medical Sciences, Arak, Iran

A - Study Design, B - Data Collection, C - Statistical Analysis, D - Data Interpretation, E - Manuscript Preparation, F - Literature Search, G - Funds Collection

Summary Background. The fears, concerns, and negative attitudes of pregnant women towards sex during pregnancy can have a negative impact on the sexual relationship and sexual performance of couples.

Objectives. We aimed to determine the effects of cognitive-behavioral counseling on misconceptions about sexual intercourse during pregnancy in pregnant women.

Material and methods. In this randomized educational study, five clinics were randomly selected in Arak, Iran. A total of 20 pregnant women who met the inclusion criteria were selected from each clinic. The Misconceptions about Sexual Intercourse during Pregnancy Questionnaire (MSIP-Q) was completed after written informed consent. Finally, twenty-two women with the lowest scores on the MSIP-Q were selected. Eleven subjects were allocated to the intervention group (cognitive-behavioral counseling), while eleven subjects were assigned to the control group. The questionnaire was also completed by the participants over a three-month interval. For statistical analysis, descriptive and inferential statistics (student's $t$-test, paired $t$-test and Fisher exact test) were calculated using SPSS software.

Results. The mean MSIP-Q score was $77.81 \pm 10.03$ in the intervention group and $71.27 \pm 8.29$ in the control group before the intervention; no significant difference was found between the groups. On the other hand, the mean MSIP-Q score was $113.3 \pm 11.16$ in the intervention group and $76.90 \pm 19.07$ in the control group following cognitive-behavioral counseling; a significant difference was found between the two groups $(p<0.001)$. Based on the findings, no significant difference was reported in the intervention group in the three-month follow-up; in fact, the effects of training remained stable.

Conclusions. This study showed that there are misconceptions about vaginal intercourse during pregnancy in Iranian women. Therefore, providing sexual health services and training during pregnancy are necessary at health clinics.

Key words: counseling, pregnancy, women.

Kheiri M, Vakilian K. Misconceptions about sexual intercourse during pregnancy: cognitive-behavioral counseling in prenatal care. Fam Med Prim Care Rev 2019; 21(2): 112-116, doi: https://doi.org/10.5114/fmpcr.2019.84545.

\section{Background}

Past studies show that most sexual problems during this period are rooted in the couple's wrong attitudes, misconceptions and misunderstandings about the physical and emotional changes during pregnancy $[1,2]$. Sexual and marital relations are known to change during pregnancy due to numerous physical and psychological transformations. Physiological and anatomical changes, such as breast tenderness or growth of the abdomen can decrease sexual desire. Psychological factors, such as changes in women's mental body image, loss of physical attraction to the partner and fear of adverse situations (e.g., abortion, fetal injury and premature labor) also effect of sexual intercourse. Negative feelings about sexual intercourse during pregnancy can either deepen the marital relationship or lead to a couple's separation $[3,4]$. On the other hand, according to published studies, if couples have pleasurable sexual intercourse during pregnancy, their communication and behaviors will improve after the infant's birth [4-7]. Although pregnancy is an important stage in women's lives and women need more emotional support during this period, a couple's in adequate information about sexual intercourse during pregnancy and their negative attitude towards sexual issues in this period can cause some problems. These problems include reduced intimacy, sexual intercourse and libido between the couple, resulting in extramarital relations during pregnancy or sexual deviation (e.g. masturbation, oral sex and anal sex) [1, 2, 8]. Sexual health education can play a positive role in preventing some of the negative consequences of sexual activity during pregnancy and can produce positive results, such as a stronger marital relationship, pleasurable sexual relations and improved confidence and conscious decision-making on both personal and interpersonal levels [9]. Since sexual desire and performance are part of pregnant women's health, efforts should be made to correct the negative attitudes towards sex during pregnancy. Therefore, further identification and elimination of dysfunctional attitudes in pregnant women seem necessary for improving their sexual health.

\section{Objectives}

In this study, we aimed to analyze the effects of cognitive-behavioral counseling on pregnant women's misconceptions about sexual intercourse during pregnancy.

\section{Material and methods}

\section{Design and settings}

The present randomized interventional study was carried out in Arak, Iran, in the winter of 2014. 
This study was approved under the ethical research number: 93-174-14.

\section{Participants and study design}

The study population consisted of pregnant women referring to health clinics in Arak.

The inclusion criteria were as follows:

1) no or only one instance of intercourse within 8 weeks after pregnancy;

2) no history of untreated sexual problems;

3) no drug addiction;

4) no use of medications affecting the sexual response;

5) absence of sexual restrictions due to medical reasons;

6) no adverse events over the past 3 months;

7) living with a permanent partner;

8) intermediate-level education (minimum);

9) age range of $18-35$ years;

10) first pregnancy;

11) gestational age of less than 12 weeks.

If the subject had a complicated pregnancy for any reason or was unwilling to continue intervention, she was excluded from the study.

Five health clinics in Arak were randomly selected via single-stage cluster sampling. In every clinic, 20 pregnant women (total: 100 pregnant women) who met the inclusion criteria were given a questionnaire, known as the Misconceptions about Sexual Intercourse during Pregnancy-Questionnaire (MSIP-Q; 36 questions).

The researcher in individual interviews with pregnant women obtained a written consent form from eligible subjects willing to participate in the study. After providing an explanation on how to complete the questionnaire, 22 participants who obtained the lowest scores on the questionnaires (score: 0-72) were selected; it should be noted that lower scores indicated misconceptions about intercourse during pregnancy. They were randomly assigned to 2 groups " $A$ " (11) and " $B$ " (11) by random blocks. The blocks were ordered and placed in a sealed packet. Cognitive-behavioral counseling sessions were held weekly in eight 90-min sessions. The intervention was implemented us- ing verbal communication, Q\&A sessions, photos, videos, PowerPoint presentations and pamphlets; additionally, a training manual was given to the participants. The content of the training sessions is described in Table 1.

The control group received no counseling except for routine prenatal care by health care workers. After the end of the counseling sessions, the post-test questionnaire on sexual attitude was completed by the intervention and control groups, and the MSIP-Q was completed again within a three-month interval by pregnant women in the control and intervention groups.

\section{Measure}

The Misconceptions about Sexual Intercourse during Pregnancy-Questionnaire (MSIP-Q; 36 questions) was prepared by researchers. It contained two sections; one about demographic features and the second about misconceptions. A panel consisting of 10 experts in fields of psychology, psychiatry, midwifery and gynecology evaluated the content validity of the questionnaire. The content validity of the scale was evaluated using both qualitative and quantitative methods. The content validity ratio (CVR) and content validity index (CVI) were estimated at 0.62 and 0.79 , respectively. To test the reliability of the questionnaire, Cronbach's alpha was also measured $(\alpha=0.86)$.

\section{Statistical analysis}

The normal distribution of the data related to the indicators was assessed, and when the parametric conditions were met, $t$-test and paired $t$-test were used. The Fisher exact test was also used for some demographic variables, using SPSS version 20. In this study, a $p$-value less than 0.05 was considered statistically significant.

\section{Results}

In order to determine whether the two groups were homogenous in terms of demographic characteristics, the subjects' history of reproductive/sexual issues was reviewed (Table 2).

\begin{tabular}{|c|c|}
\hline Sessions & \\
\hline 1 & $\begin{array}{l}\text { Introduction } \\
\text { Purposes: 1) introducing the participants to each other; 2) attracting the subjects' cooperation and gaining their confidence; } \\
\text { 3) conveying the importance of education to the subjects; 4) specifying the goals of group training; and 5) describing the out- } \\
\text { lines of the meetings for the group members. }\end{array}$ \\
\hline 2 & $\begin{array}{l}\text { Does sexual intercourse during pregnancy cause damage to the fetus? } \\
\text { Purposes: 1) being familiarized with the female anatomy; 2) being familiarized with the male anatomy; and } 3 \text { ) introduction to } \\
\text { the female anatomy during pregnancy (e.g. how the fetus grows and what factors influence the safety of the fetus). }\end{array}$ \\
\hline 3 & $\begin{array}{l}\text { Does sexual intercourse during pregnancy cause damage to the mother herself? } \\
\text { Purposes: 1) being familiarized with the physiological changes during pregnancy. }\end{array}$ \\
\hline 4 & $\begin{array}{l}\text { Is sexual intercourse a sin during pregnancy? } \\
\text { Purposes: 1) overcoming the negative attitudes of pregnant women towards sexual intercourse during pregnancy. }\end{array}$ \\
\hline 5 & $\begin{array}{l}\text { Does sexual intercourse during pregnancy improve the mental health of pregnant women? } \\
\text { Purposes: 1) defining mental health; 2) learning about common mental problems during pregnancy; } 3 \text { ) identifying the role } \\
\text { of sexual intercourse in the maintenance and promotion of mental health; } 4 \text { ) introducing the role of sex during pregnancy in } \\
\text { relieving anxiety and psychological perturbations; and 5) establishing the role of sex during pregnancy in improving mental } \\
\text { health and muscle relaxation. }\end{array}$ \\
\hline 6 & $\begin{array}{l}\text { Is sexual intercourse enjoyable during pregnancy? } \\
\text { Purposes: 1) learning about the sexual response cycle; 2) learning about sexual disorders and treatments; 3) definition of } \\
\text { sexual pleasure; 4) learning about sensitive and erogenous zones in men and women; and 5) discussing pregnant women's } \\
\text { mental image of their body. }\end{array}$ \\
\hline 7 & $\begin{array}{l}\text { Is sexual intercourse difficult during pregnancy? } \\
\text { Purposes: 1) learning about the common problems during pregnancy and the available treatment options; and 2) providing } \\
\text { training on all sexual positions during pregnancy. }\end{array}$ \\
\hline 8 & $\begin{array}{l}\text { Investigating the progress of pregnant women and reassessing their attitudes. } \\
\text { Purposes: 1) reviewing and emphasizing the content of sessions and topics discussed in the past seven weeks. }\end{array}$ \\
\hline
\end{tabular}




\begin{tabular}{|c|c|c|c|}
\hline Qualitative variables & $\begin{array}{l}\text { Intervention group } \\
n(\%)\end{array}$ & $\begin{array}{l}\text { Control group } \\
n(\%)\end{array}$ & $* p$ \\
\hline \multicolumn{3}{|l|}{ Mother's education } & \multirow{4}{*}{1.00} \\
\hline \begin{tabular}{|l|l|} 
& secondary school \\
\end{tabular} & $3(27.3)$ & $2(18.2)$ & \\
\hline high school & $5(45.4)$ & $6(54.7)$ & \\
\hline \begin{tabular}{l|l} 
& academic education \\
\end{tabular} & $3(27.3)$ & $3(27.3)$ & \\
\hline \multicolumn{3}{|l|}{ Spouse's education } & \multirow{4}{*}{0.161} \\
\hline secondary school & $4(36.4)$ & $1(9.1)$ & \\
\hline high school & $4(36.4)$ & $9(81.8)$ & \\
\hline academic education & $3(27.2)$ & $1(9.1)$ & \\
\hline \multicolumn{3}{|l|}{ Mother's occupation } & \multirow{3}{*}{1.00} \\
\hline housewife & $8(72.7)$ & $9(81.8)$ & \\
\hline employee/student & $3(27.3)$ & $2(18.2)$ & \\
\hline Spouse's occupation & $3(27.3)$ & $5(45.5)$ & \multirow{2}{*}{0.659} \\
\hline \begin{tabular}{l|l} 
& employee/worker \\
\end{tabular} & $8(72.7)$ & $6(54.5)$ & \\
\hline Marriage type & $6(54.5)$ & $8(9.1)$ & \multirow{3}{*}{0.708} \\
\hline family acquaintance & $3(27.3)$ & $2(18.2)$ & \\
\hline pre-marital relationship & $2(18.2)$ & $1(9.1)$ & \\
\hline \multicolumn{3}{|l|}{ History of sexual relationship training } & \multirow{3}{*}{1.00} \\
\hline yes & $4(36.4)$ & $3(27.3)$ & \\
\hline no & 7 (63.6) & $8(72.8)$ & \\
\hline \multicolumn{3}{|l|}{ Sexual information sources } & \multirow{5}{*}{0.161} \\
\hline books & $8(72.8)$ & $6(54.5)$ & \\
\hline family physician & $1(9.1)$ & $2(18.2)$ & \\
\hline radio and tv & 0 & $3(27.3)$ & \\
\hline others & $2(18.2)$ & 0 & \\
\hline Quantitative variables & $\begin{array}{l}\text { Intervention group } \\
\text { Mean } \pm \text { SD }\end{array}$ & $\begin{array}{l}\text { Control group } \\
\text { Mean } \pm \text { SD } \\
\end{array}$ & $\pm p$ \\
\hline Mother's age & $22.72 \pm 3.95$ & $25.81 \pm 3.48$ & 0.135 \\
\hline Duration of marriage (years) & $3.54 \pm 3.23$ & $5.36 \pm 3.41$ & 0.215 \\
\hline Income status $(1,000,000 \mathrm{R})$ & $8.68 \pm 2.79$ & $8.63 \pm 1.28$ & 0.961 \\
\hline Gravid & $1.18 \pm 0.40$ & $1.27 \pm 0.46$ & 0.631 \\
\hline Number of living children & $0.18 \pm 0.40$ & $0.27 \pm 0.46$ & 0.642 \\
\hline
\end{tabular}

$\pm t$-test; ${ }^{*}$ Fisher exact test.

\begin{tabular}{|c|c|c|c|c|c|}
\hline \multirow{2}{*}{$\begin{array}{l}\text { Groups } \\
\text { domains }\end{array}$} & \multicolumn{2}{|c|}{ Intervention } & \multicolumn{2}{|c|}{ Control } & \multirow[t]{2}{*}{$* p$} \\
\hline & Mean & SD & Mean & SD & \\
\hline 1. Does sexual intercourse during pregnancy cause damage to the fetus? & 21.96 & 2.28 & 13.59 & 5.46 & 0.001 \\
\hline 2. Does sexual intercourse during pregnancy cause damage to the mother herself? & 13.59 & 2.69 & 11.34 & 3.85 & 0.001 \\
\hline 3. Is sexual intercourse a sin during pregnancy? & 18.45 & 2.20 & 14.25 & 4.86 & 0.008 \\
\hline $\begin{array}{l}\text { 4. Does sexual intercourse during pregnancy increase the mental health of preg- } \\
\text { nant women? }\end{array}$ & 18.81 & 2.99 & 16.96 & 3.84 & 0.230 \\
\hline 5. Is sexual intercourse enjoyable during pregnancy? & 14.16 & 2.89 & 12.43 & 3.64 & 0.232 \\
\hline 6. Is sexual intercourse difficult during pregnancy? & 16.34 & 3.72 & 8.15 & 2.75 & 0.001 \\
\hline Total MSIP-Q score (after the last session) & \pm 113.36 & 11.16 & 76.72 & 19.07 & 0.001 \\
\hline Total MSIP-Q score in the three-month follow-up & \pm 111.73 & 10.25 & 69.90 & 17.63 & 0.001 \\
\hline After education and three-month follow-up & $\pm p=0.480$ & & & & \\
\hline
\end{tabular}

$* t$-test; $\pm t^{2}=0.48$.

Comparison of the two groups in terms of demographic information and reproductive/sexual history showed that they were similar to each other, and there was no significant difference between the groups $(p>0.05)$.

In this study, the attitude of pregnant women was categorized into six domains. Each domain was compared between the intervention and control groups. Following counseling, all domains of sexual attitude were significantly different between the two groups $(p<0.001)$, except for two domains, i.e. "sexual intercourse during pregnancy increases the mental health of pregnant women" and "sexual intercourse is enjoyable during pregnancy" (Table 3). The total average MSIP-Q scores were also significant between the two groups after eight weekly sessions $(p<0.001)$. In other words, pregnant women's misconceptions towards sexual intercourse were lower during pregnancy in the intervention group. 
Three months later, sexual misconceptions were re-evaluated in both groups. The frequency of coitus was also assessed after three months. The results showed no significant difference in the intervention group after the three-month follow-up, and the effect of educational intervention was found to be stable $(p=0.480)$ (Table 3$)$. The mean coitus was also $4.6 \pm 1.76$ and $2.4 \pm 1.14$, respectively, in the counseling and control groups $(p=0.03)$

\section{Discussion}

The present study showed that counseling corrected misconceptions about intercourse during pregnancy, such as the fear of harm to the fetus, fear of harm to the mother, the sinful nature of sex during pregnancy and stress during sexual intercourse.

A study by Bayrami et al. showed that fear of harm to the fetus and infection was the most common problem, and sexual desire and activity was reduced to $1.61 \%$ from $6.58 \%$ during pregnancy in comparison with the pre-pregnancy period [10]. In addition, a study conducted by Naim and Bhutton pregnant women's sexual activity showed that $45.4 \%$ of the subjects believed that intercourse is harmful to the fetus, and $22.7 \%$ believed that sexual activity leads to abortion [11].

Undoubtedly, the pattern of changes in sexual activity during pregnancy is influenced by misbeliefs and misconceptions regarding physical and psychological changes during this period [8]. Fabamwo and Akinola showed that the most common reasons for abstaining from sex were fear of compilations (35.3\%), $17.6 \%$ did not appeal to them, and $8.8 \%$ said it is too painful [12].

On the other hand, the findings in this study showed a positive role of education in increasing the chance of intercourse after three months' education. Pauleta et al. reported that $13.9 \%$ of couples ceased coitus during pregnancy in Taiwan. In this article, variations in sexual activity, such as manual sex, anal intercourse and coital adjustments were made by couples [13].

The pattern of changes in sexual activity during pregnancy was found to be related to misconceptions about physical and psychological changes during this period. The results of the mentioned studies, as well as the present research, showed that pregnant women's attitude towards sexual activity originates from misconceptions rooted in their misinformation [14]. Vakilian et al., in a randomized clinical trial study on 100 pregnant women, showed that sexual counseling during pregnancy, whereas the control group increased sexual function during pregnancy. They used a cognitive approach for improving the misbelieves of pregnant women [4]. Contrary to this, Wannakosit and Phupong didn't report any improvement in sexual function during education compared to those of the control group [15]. A systematic review in 56 studies showed that couples postpone vaginal intercourse eight weeks after childbirth and increased their efforts in other sexual behaviors [16]. A qualitative study on Taiwanese women pointed towards a negative experience during vaginal sex, such as dyspareunia, uterine discomfort, dry vaginal mucosa, pain in the pelvis and fatigue [17]. Vakilian et al. pointed out that counseling during pregnancy plays an important role in decreasing the discomfort of sexual intercourse during pregnancy [4].

Today, social and cultural issues, together with inadequate sexual training by the healthcare system, are proposed as the main obstacles against the promotion of knowledge and positive attitudes towards sexual health.

\section{Conclusions}

This study showed that there are misconceptions about vaginal intercourse during pregnancy in Iranian women. Therefore, providing sexual health services and training during pregnancy are necessary at health clinics. In addition, there is a major need for providing proper consultation for pregnant women in order to improve their physical and emotional compliance with changes during pregnancy and increase a couple's sexual knowledge when overcoming their negative attitudes.

Acknowledgments. This study was extracted from a Master's thesis of the Arak University of Medical Sciences (ethical code: 93-174-14). Hereby, we would like to thank the research deputy of the Faculty of Nursing and Midwifery and the Arak University of Medical Sciences for the scientific and ethical approval of the study and their financial support.

Source of funding: This study was financially supported by the deputy of research of Arak University of Medical Sciences, Arak, Iran. Conflicts of interest: The authors declare no conflicts of interest.

\section{References}

1. Yoo H, Bartle-Haring S, Day R, et al. Couple communication, emotional and sexual intimacy, and relationship satisfaction. J Sex Marital Ther 2014; 40(4): 275-293.

2. Efe H, Bozkurt M, Sahin L, et al. The effects of pregnancy on the sexual life of Turkish women. Proc Obstet Gynecol 2014; 4(1): 5 .

3. Trutnovsky G, Haas J, Lang U, et al. Women's perception of sexuality during pregnancy and after birth. J Obstet Gynaecol 2006; 46(4): 282-287, doi: http://doi: 10.1111/j.1479-828X.2006.00592.x

4. Vakilian K, Kheiri M, Majidi A. Effect of cognitive-behavioral sexual counseling on female sexual function during pregnancy: an interventional study. IJWHR 2018; 6: 369-373, doi: 10.15296/ijwhr.2018.60.

5. DeJudicibus M, McCabe M. Psychological factors and the sexuality of pregnant and postpartum women J Sex Res 2002; 39: 94-103, doi: http://dx.doi.org/10.1080/00224490209552128.

6. Johnson C. Sexual health during pregnancy and the postpartum (CME). J Sex Med 2011; 8: 1267-1284, doi: http://dx.doi: 10.1111/j.17436109.2011.02223.x

7. Saduck BJ, Sadock VA, Ruiz P. Kaplan and Sadock's comprehensive textbook of psychiatry. 11th ed. Philadelphia: Lippincott Williams and Wilkins; 2012.

8. Shojaa M, Jouybari L, Sanagoo A. The sexual activity during pregnancy among a group of Iranian women. Arch Gynecol Obstet 2009; 279(3): 353-356, doi: https://doi.org/10.1007/s00404-0080735-z.

9. Moniek M, Stephanie B, Jacques J. Cognitive behavioral therapy for sexual dysfunctions in women. Psychiatr Clin N Am 2010; 33(3): 595-610, doi: https://doi.org/10.1016/j.psc.2010.04.010.

10. Bayrami R, Satarzadeh N, Ranjbar-Kouchaksarei F, et al. Male sexual behavior and its relevant factors during the partner's pregnancy. Res Sci J Ardabil Univ Med Sci 2009; 8(30): 356-363 (in Persian).

11. Naim M, Bhutto E. Sexuality during pregnancy in Pakistani women. J Pak Med Assoc 2000; 50(1): 38-43.

12. Fabamwo AO, Akinola OI. Sexuality and sexual experience among women with uncomplicated pregnancies in Ikeja Lagos. JMMS 2011; 2(6): 894-899.

13. Pauleta J, Pereire N, Graca L. Sexuality during pregnancy J Sex Med 2010; 7: 136-42, doi: https://doi: 10.1111/j.1743-6109.2009.01538.x. 
14. Sossah L. Sexual behavior during pregnancy: a descriptive correlational study among pregnant women. EJRMS 2014; 2(1): 16-27.

15. Wannakosit S, Phupong V. Sexual behavior in pregnancy: comparing between sexual education group and nonsexual education group. J Sex Med 2010; 7(10): 3434-3438, doi: 10.1111/j.1743-6109.2010.01715.x.

16. Jawed-Wessel S, Sevick E. The impact of pregnancy and childbirth on sexual behaviors: a systematic review. J Sex Res 2017; 54(4-5): 411-423, doi: doi.org/10.1080/00224499.2016.1274715.

17. Liu HI, Hsu P, Chen KH. Sexual activity during pregnancy in Taiwan: a qualitative study. Sex Med 2013; 1(2) 54-61, doi: 10.1002/sm2.13.

Tables: 3

Figures: 0

References: 17

Received: 10.10 .2018

Reviewed: 5.11.2018

Accepted: 17.01.2019

Address for correspondence:

Katayon Vakilian, PhD, Assoc. Prof.

Peyambare Azam Campus

Arak University of Medical Sciences

Sardasht street

Arak

Iran

Tel.: 08634173505

E-mail: dr.kvakilian@arakmu.ac.ir 